adults were based on university students and/or self-selected participants. In summary, intense or frequent mobile phone use was seen to be associated with a broad spectrum of mental health outcomes, e.g. depressive symptoms and sleep problems. Mobile phone use at bedtime was associated with shorter sleep duration and lower sleep quality. 'Problematic use', i.e., mobile phone use connected to behavioural addiction or pathological usage, was associated with several negative outcomes such as depression, anxiety, and sleep problems. Discussion Research studies show associations between mobile phone use and mental health outcomes. However, there is need for more studies of good quality; with longitudinal design, objective measurements, and well-defined study populations, in order to draw valid conclusions about possible causal associations between mobile phone use and mental health symptoms.

\section{A CLINICAL APPROACH OF WORKAHOLISM}

Quentin Durand-Moreau, Brice Loddé, Jean-Dominique Dewitte. Occupational and Environmental Diseases Centre, University Hospital of Brest, Brest, France

\subsection{6/oemed-2018-ICOHabstracts. 1643}

Introduction To date, no definition of workaholism can be considered as consensual. Some authors propose a behavioural approach with a cognitive side (an inner drive) and a behavioural side (working excessively). But with this perspective, the place for subjectivity is rather small and clinical descriptions of workaholism are scarce. In this context, we aimed to describe case-reports of patients suffering from workaholism. Methods We describe case-reports from patients who went to the occupational disease centre of Brest University Hospital, France between November 2013 and July 2016. Consultations were performed by a single physician, specialised in workrelated mental disorders with the methods of clinical occupational medicine, as described by Davezies. Included patients were those with a diagnostic of workaholism. The diagnostic has been performed regarding Goodman's common criteria of addictions.

Results During the period of interest, 168 patients have consulted for a work-related mental trouble. Of these, 8 patients suffered from workaholism (4 female and 4 male). Mean age at diagnostic time was 44.1 years. Three clinical situations will be detailed: a 41 years old door-to-door canvasser selling goods for craft workers, a 51 years old nurse in a hospital, and a 30 years old saleswoman in a cooperative selling farming goods.

Discussion Clinical descriptions allow to highlight some characteristic elements among patients suffering from workaholism: variable remuneration linked to the worker's commercial performance, the use of a professional telephone during weekends and free time, storage of professional stuff at home, huge ambivalence between the will to go on working while knowing that work is degrading health, addictive comorbidities (tobacco, alcohol consumption, anorexia). There is a need for a work sociopsychologic approach of the situation, associating individual healthcare and improvements on the working environment. The latter part is often lacking but it offers the best long-term efficacy.

\section{WHICH PSYCHOSOCIAL RISK FACTORS AT WORK CONTRIBUTE TO THE ONSET OF STRESS-RELATED DISORDERS? A SYSTEMATIC REVIEW AND META- ANALYSIS}

GJ de Groene* ${ }^{*}$ K Nieuwenhuijsen, MH Frings-Dresen, HF van der Molen. Academic Medical Centre, Department Coronel Institute of Occupational Health/Netherlands Centre for Occupational Diseases, Amsterdam Public Health research institute, Amsterdam, The Netherlands

\subsection{6/oemed-2018-ICOHabstracts. 1644}

Introduction Psychosocial risk factors at work are known to contribute to the onset of stress-related disorders (SRDs). Evidence about work-related psychosocial risk factors is necessary to select and implement preventive workplace interventions. The aim of our review was to identify psychosocial risk factors at work which are associated with the onset of SRDs, updating a prior review with evidence up until 2008.

Methods A systematic literature search was conducted for the period January 2008 to October 2014 in Medline, Embase and PsycINFO. Inclusion criteria were: prospective study design, exposure of workers to psychosocial risk factors, and an SRD outcome. Data from the studies included were pooled with the results of a previous systematic review. The quality of the evidence was assessed using an adapted GRADE procedure.

Result The updated review consisted of twelve studies. The search yielded 5300 articles. Five articles met the inclusion criteria and were added to the seven of the previous review.

Evidence of high quality was found for the risk factors of 'effort-reward imbalance', 'high psychological demands', 'low decision authority', 'low co-worker support', 'low supervisor support', 'low procedural justice' and 'low relational justice', while evidence of moderate quality was found for 'high emotional demands' contributing to the onset of an SRD.

'Effort-reward imbalance' and 'low procedural justice' exhibited the largest association with SRDs, with Odds Ratios of 2.0 (95\% CI: 1.81 to 2.22 ) and 1.8 (95\% CI: 1.60 to 1.98), respectively.

Discussion Several psychosocial work-related risk associated with the onset of SRDs were established, confirming prior findings. Awareness of these risk factors could be the starting point for the selection of preventive interventions to reduce work-related SRDs.

\section{A STUDY ON JOB STRESS AND RELATED HEALTH PROBLEMS AMONG HOSPITAL NURSES IN INDIA}

Bishwadeep Paul*. Siemens Ltd, Mumbai, India

\subsection{6/oemed-2018-ICOHabstracts. 1645}

Introduction Stress in nurses is an endemic problem. It contributes to health problems in nurses and decreases their efficiency. Documenting the causes and extent of stress in any healthcare unit is essential for successful interventions. This exploratory study attempted to establish the existence and extent of work stress in nurses in a hospital setting, to identify the major sources of stress, and to find the incidence of psychosomatic illness related to stress. In addition it was 